\title{
Structural and Optical Properties of Silicon Nanowire Arrays Fabricated by Metal Assisted Chemical Etching With Ammonium Fluoride
}

\section{OPEN ACCESS}

Edited by:

Thierry Djenizian,

École des Mines de Saint-Étienne,

France

Reviewed by:

Kui-Qing Peng,

Beijing Normal University, China

Jeffery L. Coffer,

Texas Christian University,

United States

*Correspondence:

Kirill A. Gonchar

k.a.gonchar@gmail.com

Specialty section:

This article was submitted to

Chemical Engineering,

a section of the journal

Frontiers in Chemistry

Received: 20 October 2018 Accepted: 14 December 2018

Published: 04 January 2019

Citation:

Gonchar KA, Kitaeva VY, Zharik GA, Eliseev AA and Osminkina LA (2019)

Structural and Optical Properties of Silicon Nanowire Arrays Fabricated by Metal Assisted Chemical Etching With

Ammonium Fluoride.

Front. Chem. 6:653.

doi: 10.3389/fchem.2018.00653

\author{
Kirill A. Gonchar ${ }^{1 *}$, Veronika Y. Kitaeva ${ }^{1}$, George A. Zharik ${ }^{1}$, Andrei A. Eliseev ${ }^{2,3}$ and \\ Liubov A. Osminkina ${ }^{1,4}$
}

${ }^{1}$ Physics Department, Lomonosov Moscow State University, Moscow, Russia, ${ }^{2}$ Chemistry Department, Lomonosov Moscow State University, Moscow, Russia, ${ }^{3}$ Faculty of Materials Science, Lomonosov Moscow State University, Moscow, Russia, ${ }^{4}$ Institute for Biological Instrumentation of Russian Academy of Sciences, Pushchino, Russia

Here we report on the metal assisted chemical etching method of silicon nanowires (SiNWs) manufacturing, where the commonly used hydrofluoric acid (HF) has been successfully replaced with ammonium fluoride $\left(\mathrm{NH}_{4} \mathrm{~F}\right)$. The mechanism of the etching process and the effect of the $\mathrm{pH}$ values of $\mathrm{H}_{2} \mathrm{O}_{2}: \mathrm{NH}_{4} \mathrm{~F}$ solutions on the structural and optical properties of nanowires were studied in detail. By an impedance and Mott-Schottky measurements it was shown that silver-assisted chemical etching of silicon can be attributed to a facilitated charge carriers transport through $\mathrm{Si} / \mathrm{SiO} / \mathrm{Ag}$ interface. It was shown that the shape of nanowires changes from pyramidal to vertical with $\mathrm{pH}$ decreasing. Also it was established that the length of SiNW arrays non-linearly depends on the $\mathrm{pH}$ for the etching time of $10 \mathrm{~min}$. A strong decrease of the total reflectance to $5-10 \%$ was shown for all the studied samples at the wavelength $<800 \mathrm{~nm}$, in comparison with crystalline silicon substrate (c-Si). At the same time, the intensities of the interband photoluminescence and the Raman scattering of SiNWs are increased strongly in compare to c-Si value, and also they were depended on both the length and the shape of SiNW: the biggest values were for the long pyramidal nanowires. That can be explained by a strong light scattering and partial light localization in SiNWs. Hereby, arrays of SiNWs, obtained by using weakly toxic ammonium fluoride, have great potential for usage in photovoltaics, photonics, and sensorics.

Keywords: silicon nanowires, impedance, total reflectance, photoluminescence, Raman scattering

\section{INTRODUCTION}

In recent decades, the possibility of using silicon nanowires (SiNWs) in sensorics (Cui et al., 2001; Wang and Ozkan, 2008; Cao et al., 2015; Georgobiani et al., 2018), photovoltaics (Kelzenberg et al., 2008; Stelzner et al., 2008; Sivakov et al., 2009), photonics (Brönstrup et al., 2010), and micro-and optoelectronics (Föll et al., 2010; Yang et al., 2010) has been shown. Nanowires are usually obtained as a result of anisotropic growth of a 1D crystal on a nanometer scale. The first SiNWs were fabricated via bottom-up approach by vapor-liquid-solid (VLS) method with different noble metals (mostly gold) as catalyst (Wagner and Ellis, 1964). Metal-assisted chemical etching (MACE) of silicon was observed for the first time in the 1990s, when a cleaning solution $\mathrm{HF}-\mathrm{H}_{2} \mathrm{O}_{2}-\mathrm{H}_{2} \mathrm{O}$ was used to remove metal impurities from the silicon substrate (c-Si) (Morinaga et al., 1995). Then this method was adapted for luminescent porous silicon formation (Gorostiza et al., 1999; 

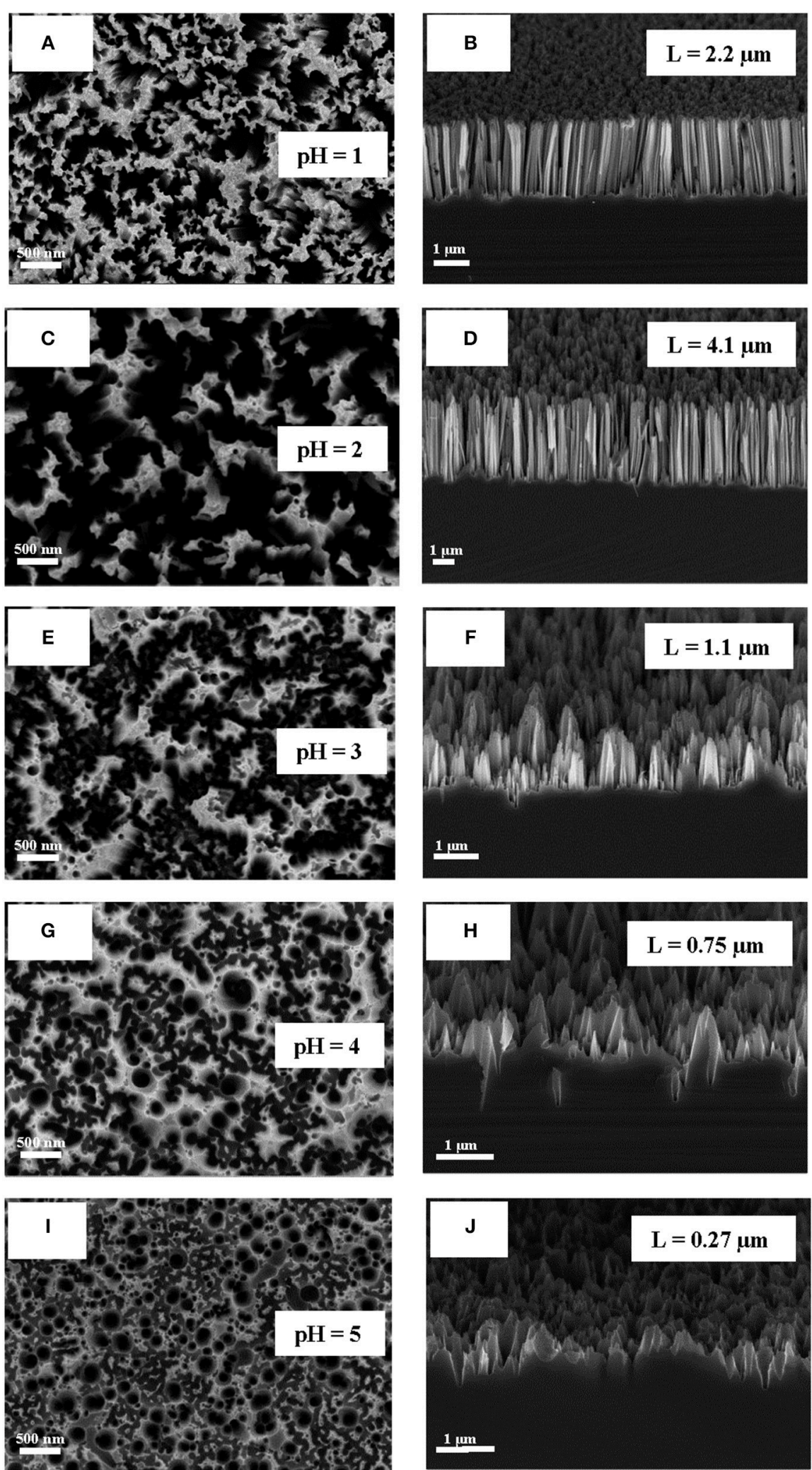

FIGURE 1 | (A,C,E,G,I) SEM micrographs of SiNWs with different pH of $\mathrm{H}_{2} \mathrm{O}_{2}: \mathrm{NH}_{4} \mathrm{~F}$ (view from above); (B,D,F,H,J) SEM cross-sectional micrographs of SiNWs with different $\mathrm{pH}$ of $\mathrm{H}_{2} \mathrm{O}_{2}: \mathrm{NH}_{4} \mathrm{~F}$. 
Li and Bohn, 2000; Chattopadhyay et al., 2002). In 2002, Peng et al for the first time adapted it for high aspect ratio SiNWs fabrication and systematically investigated the mechanism and further develop it into a new mciro/nanofabrication method (Peng et al., 2002, 2006, 2008). Also MACE method of SiNWs fabrication was systematically investigated in Nahidi and Kolasinski (2006), Sivakov et al. (2010), Bai et al. (2012), and Dawood et al. (2012). Usually in MACE such catalysts, as nanoparticles of $\mathrm{Au}$ (Li and Bohn, 2000; Dawood et al., 2012), Ag (Sivakov et al., 2010), or Pt (Li and Bohn, 2000; Chattopadhyay et al., 2002) and such oxidizing agents as $\mathrm{H}_{2} \mathrm{O}_{2}$ ( $\mathrm{Li}$ and Bohn, 2000; Sivakov et al., 2010; Dawood et al., 2012), $\mathrm{KMnO}_{4}$ (Bai et al., 2012; Jiang et al., 2017), or $\mathrm{Fe}\left(\mathrm{NO}_{3}\right)_{3}$ (Nahidi and Kolasinski, 2006), are used in the process. SiNWs, which were fabricated by a standard MACE procedure, are found to possess such optical properties as extremely low total reflection (Gonchar et al., 2012), enhancement of Raman scattering and interband photoluminescence (PL) (Gonchar et al., 2014). However, HF, that is surely used in the MACE, is toxic and dangerous, and may also lead to hypocalcemia and hypomagnesemia (Bertolini, 1992). Therefore, it is very important, with a view to the future largescale production of SiNWs, to study the possibilities of modifying the MACE method using safer and less toxic chemicals.

It is well-known that aqueous solutions of ammonium fluoride $\left(\mathrm{NH}_{4} \mathrm{~F}\right)$ can be used to dissolve $\mathrm{SiO}_{2}$, and the etching rate depends on the concentration of $\mathrm{NH}_{4} \mathrm{~F}$ and the $\mathrm{pH}$ of the solutions (Judge, 1971). Thus, $\mathrm{NH}_{4} \mathrm{~F}$ is shown can be used as an alternative to HF in the method of electrochemical etching in the manufacture of porous silicon, and the structural properties of the resulting porous silicon depend on the $\mathrm{pH}$ of the $\mathrm{NH}_{4} \mathrm{~F}$ solution used: at $\mathrm{pH}=4.5$ a pebble-like surface was formed, and at lower $\mathrm{PH}$ a nanoporous silicon layers were formed (Dittrich et al., 1995). Recently, the possibility of using $\mathrm{NH}_{4} \mathrm{~F}$ in the MACE process has been also shown, and optical properties of SiNW, formed using $\mathrm{NH}_{4} \mathrm{~F}$, differed little from nanowires formed by

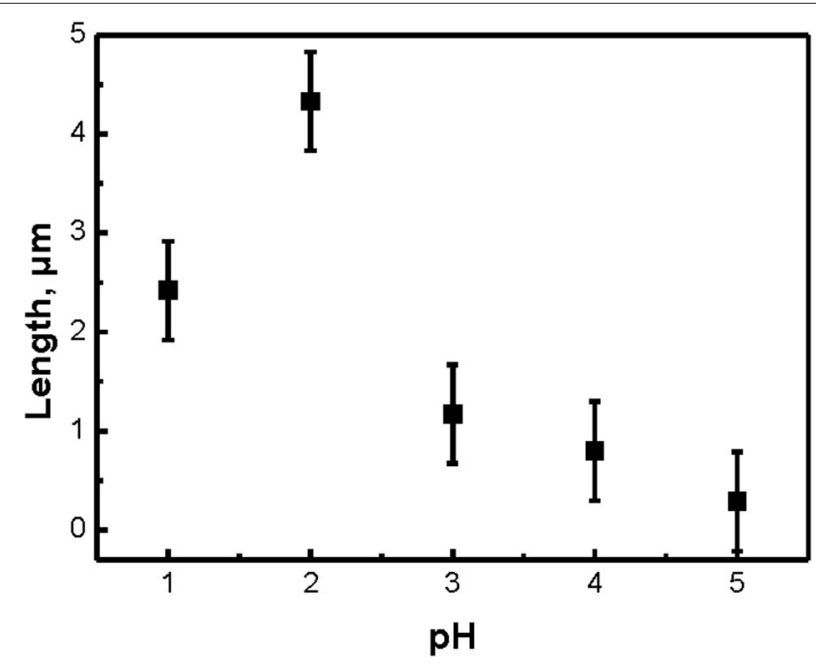

FIGURE 2 | The dependence of the length of SiNWs with different pH value of $\mathrm{H}_{2} \mathrm{O}_{2}: \mathrm{NH}_{4} \mathrm{~F}$. standard MACE technology with HF (Gonchar et al., 2016). However, the mechanism of the etching process and the influence of the $\mathrm{pH}$ of the etching solution on the structural and optical properties of SiNW remain open.

In this work, the etching process mechanism and the effect of $\mathrm{pH}$ values of $\mathrm{H}_{2} \mathrm{O}_{2}: \mathrm{NH}_{4} \mathrm{~F}$ solutions on the structural and optical properties of SiNWs were studied using impedance measurements and Mott-Schottky analysis, as well as total reflectance, interband photoluminescence and Raman scattering intensities measurements.

\section{METHODS}

The samples of SiNWs were produced by MACE of (100)oriented p-type c-Si wafer with resistivity of $10-20 \Omega \bullet c m$. HF was replacement on $\mathrm{NH}_{4} \mathrm{~F}$ in all reactions. The $\mathrm{PH}$ value was

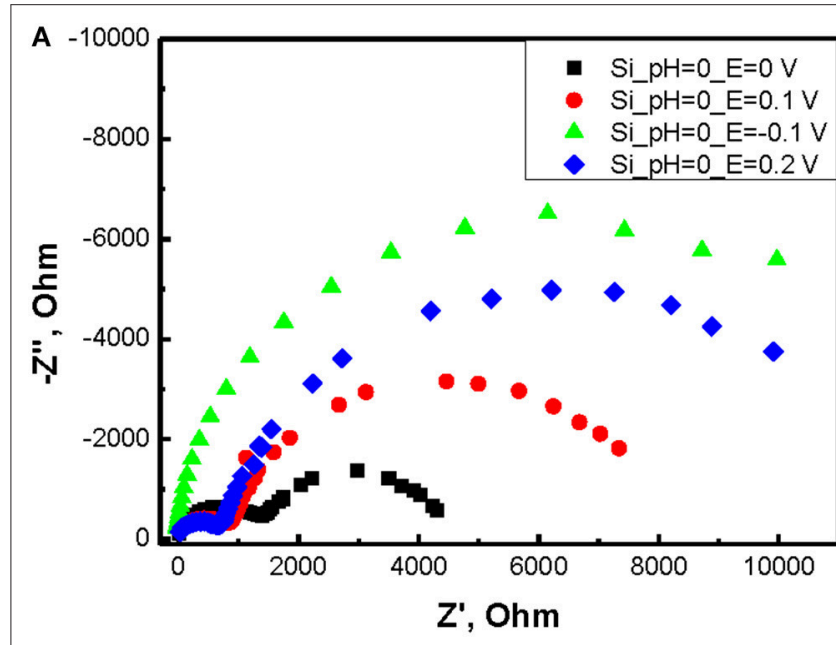

B

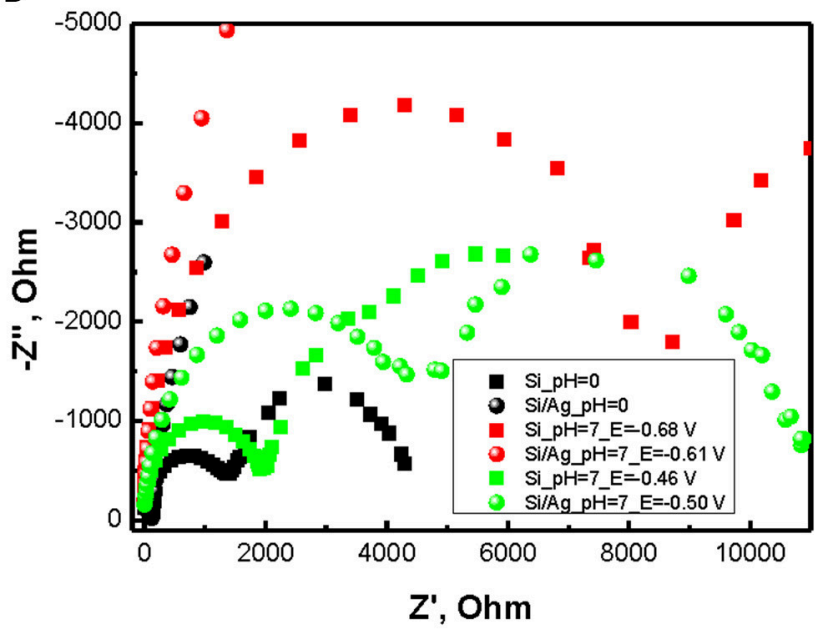

FIGURE 3 | (A) Impedance spectra of p-doped silicon in 5M NH4F/1M $\mathrm{H}_{2} \mathrm{SO}_{4}$ electrolyte containing $30 \%$ of $\mathrm{H}_{2} \mathrm{O}_{2}$. (B) impedance spectra for different interfaces and $\mathrm{pH}$. 
controlled by $\mathrm{PH}$ indicator. Prior to the MACE procedure, $\mathrm{c}-\mathrm{Si}$ wafers were rinsed in $2 \% \mathrm{HF}$ solution for $1 \mathrm{~min}$ to remove a native silicon oxide. In the first stage of MACE process, c-Si wafers were placed in the aqueous solution of $0.02 \mathrm{M}$ of silver nitrate $\left(\mathrm{AgNO}_{3}\right)$ and $5 \mathrm{M}$ of $\mathrm{NH}_{4} \mathrm{~F}$ in the volume ratio of $1: 1$ for $30 \mathrm{~s}$ and a thin $(\sim 100 \mathrm{~nm})$ layers of Ag nanoparticles were deposited on the surface of the wafers. In the second stage, c-Si wafers with Ag nanoparticles were placed in the etching solution containing $5 \mathrm{M}$ of $\mathrm{NH}_{4} \mathrm{~F}$ and $30 \% \mathrm{H}_{2} \mathrm{O}_{2}$ in the volume ratio of $10: 1$ for $10 \mathrm{~min}$. The $\mathrm{PH}$ value of the $\mathrm{NH}_{4} \mathrm{~F}$ aqueous solution was changed by adding of $\mathrm{H}_{2} \mathrm{SO}_{4}$ droplets and varied in the range from 1 to 5 . All the etching stages were carried out at room temperature. After the etching process all the samples were rinsed in de-ionized water and dried at room temperature. The main etching reaction the same that was described in Zhang et al. (2008):

$$
\mathrm{Si}+\mathrm{H}_{2} \mathrm{O}_{2}+6 \mathrm{~F}^{-}+4 \mathrm{H}^{+}=\mathrm{SiF}_{6}^{2-}+4 \mathrm{H}_{2} \mathrm{O},
$$

however in our case the ions of $\mathrm{F}^{-}$and $\mathrm{H}^{+}$were obtained not from the dissociation of $\mathrm{HF}$ as in standard MACE procedure, but from the dissociation of $\mathrm{NH}_{4} \mathrm{~F}$ and $\mathrm{H}_{2} \mathrm{SO}_{4}$. Ag nanoparticles played the role of catalysts for the etching process. The removal of Ag nanoparticals from SiNW arrays was performed by immersing in concentrated $(65 \%)$ nitric acid $\left(\mathrm{HNO}_{3}\right)$ for $15 \mathrm{~min}$.

The structures of SiNWs were studied by a scanning electron microscope (SEM) of Carl Zeiss SUPRA 40 FE-SEM. Impedance spectra and Mott-Schottky measurements were performed using Solartron 1287 electrochemical interface and Solartron 1255B frequency response analyzer. All the measurements were carried out in three-electrode teflon cell using $\mathrm{Ag} / \mathrm{AgCl}$ reference electrode joined through polypropylene Luggin capillary. The total reflectance (which includes both diffuse and specular components) spectra at the wavelength from 250 to $850 \mathrm{~nm}$ were studied with an integrating sphere on a Perkin Elmer spectrometer Lambda 950. The interband PL and Raman spectra were measured in a back scattering geometry with a Fouriertransform infrared (FTIR) spectrometer of Bruker IFS $66 \mathrm{v} / \mathrm{S}$ equipped with a FRA-106 unit. Excitation was carried out by $\mathrm{cw}$ $\mathrm{Nd}$ :YAG laser at the wavelength $1.064 \mu \mathrm{m}$ (excitation intensity was $100 \mathrm{~mW}$ and spot size was $2 \mathrm{~mm}$ ). All experiments were carried out in air at room temperature.

TABLE 1 | Open circuit potential (OCP) and flat band potential for different interfaces and $\mathrm{pH}$

\begin{tabular}{lcc}
\hline Sample & Open circuit potential, v & Flat band potential, v \\
\hline Si_pH $=0-1$ & -0.17 & -0.26 \\
Si_pH $=2-3$ & -0.25 & -0.34 \\
Si_pH $=4-5$ & -0.34 & -0.46 \\
Si_pH $=6-7$ & -0.55 & -0.75 \\
Si/Ag_pH $=0-1$ & -0.14 & -0.32 \\
Si/Ag_pH $=2-3$ & -0.30 & -0.38 \\
Si/Ag_pH $=4-5$ & -0.33 & -0.39 \\
Si/Ag_pH $=6-7$ & -0.42 & -0.50
\end{tabular}

\section{RESULTS AND DISCUSSION}

Typical SEM microphotographs of SiNW layers, which were obtained by using different $\mathrm{pH}$ of the etching solution $\mathrm{H}_{2} \mathrm{O}_{2}: \mathrm{NH}_{4} \mathrm{~F}$ are presented in Figure 1. Note, that for $\mathrm{pH}=6$ or 7 the etching rate was very slow and the optical properties of SiNWs are slightly different from c-Si substrate. It is seen from the Figure 1, that the shape of SiNW is changing from vertical cylinders to pyramidal like structures with $\mathrm{pH}$ increasing. Figure 2 presented the dependence of the length of SiNWs from the $\mathrm{pH}$ value. The length of SiNW is maximum at $\mathrm{pH}=2$ and then decreases with increasing $\mathrm{pH}$. SiNW porosity was calculated by using Bruggeman model (Bruggeman, 1935) and was approximately $50-60 \%$ for all samples.

Impedance spectra of p-doped silicon in $5 \mathrm{M} \mathrm{NH} \mathrm{NH}_{4} \mathrm{~F} / 1 \mathrm{M}$ $\mathrm{H}_{2} \mathrm{SO}_{4}$ electrolyte containing $30 \%$ of $\mathrm{H}_{2} \mathrm{O}_{2}$ illustrate two semicircles with series resistance close to zero (Figure 3A). Thus, an equivalent circuit for the cell can be represented by parallel RC circuits connected in series. Applying positive bias vs. open circuit potential (OCP) leads to a first element resistivity decrease while increasing the radius of the second semicircle. Applying negative potential leads to first semicircle radius growth. As soon as Warburg resistance can be considered negligible in concentrated $\mathrm{NH}_{4} \mathrm{~F} / \mathrm{H}_{2} \mathrm{SO}_{4}$ solution, the presence of the second semicircle can be referred to an electric double layer with non-equilibrium silicon oxide formed at the surface

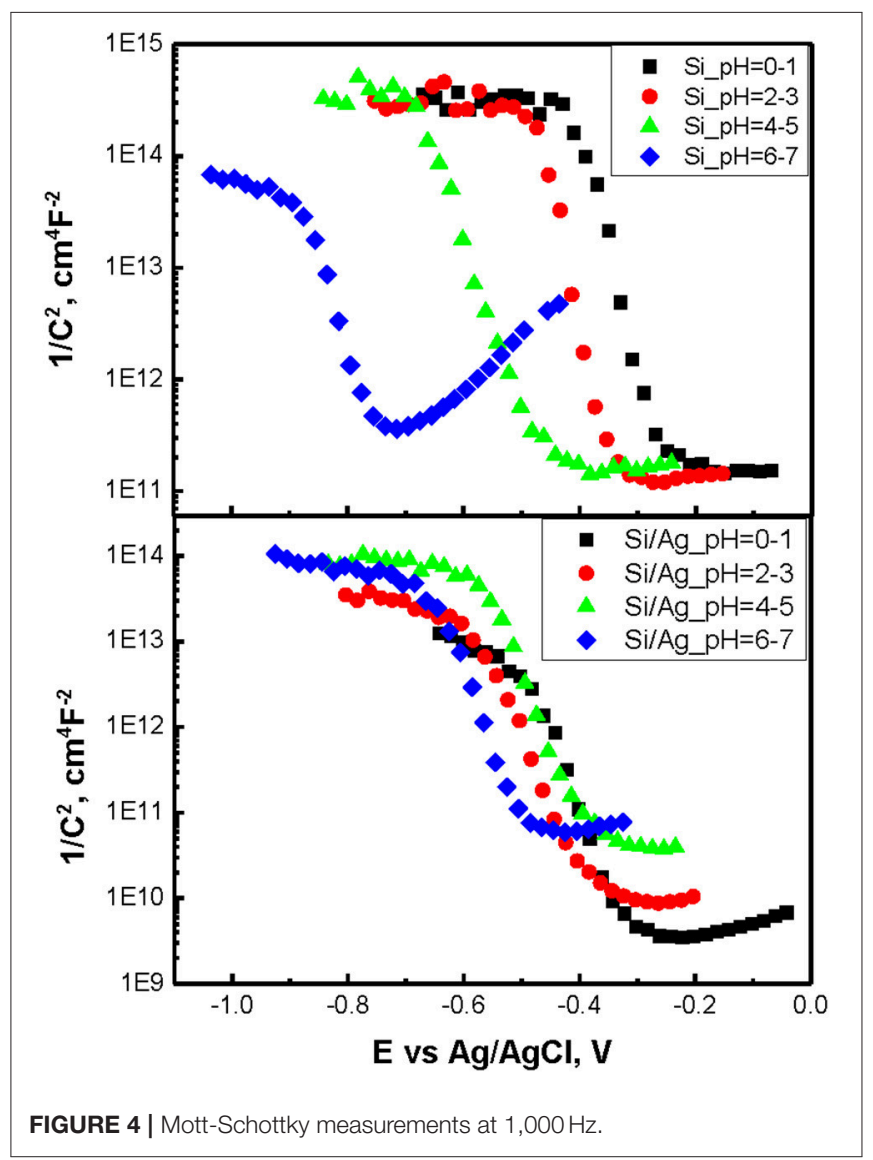


of $\mathrm{Si}$ electrode. Resistivity of $\mathrm{SiO}_{\mathrm{x}}$ layer predictably increases with shifting to positive potentials vs. $\mathrm{Ag} / \mathrm{AgCl}$ reference due to growing layer thickness. As soon as first semicircle appear at higher frequencies (typically $>1,000 \mathrm{~Hz}$ ) it can only correspond to the processes at $\mathrm{Si} / \mathrm{SiO}_{\mathrm{x}}$ interface. This parallel RC element can be ascribed to the accumulation layer in Si resulting in downward bending of the valence and the conduction bands. Decreasing the radius of this semicircle with shifting to positive potentials is than well-explained by band flattening in p-doped silicon.

Notably both the $\mathrm{SiO}_{\mathrm{x}}$ layer thickness and electrolyte potential are strongly affected by $\mathrm{pH}$. With increasing $\mathrm{pH}$ of electrolyte OCP of the cell decreases reducing silicon oxidation rate (Figure 3B, Table 1). However, the radius of the second RC elements grows due to lower dissolution rate of silicon dioxide resulting in higher capacitance of the layer (Figure 3B).

Addition of silver particles to the system introduces a number of changes to the impedance spectra. First, Z" at high frequencies strongly decreases implying lowering of the capacitance at $\mathrm{Si} / \mathrm{SiO}_{\mathrm{x}}$ interface. Secondly, the radius of the second semicircle greatly increases indicating larger thickness of $\mathrm{SiO}_{\mathrm{x}}$ layer. These effects are associated with inhomogeneous nature of $\mathrm{Ag} / \mathrm{Si}$ electrodes where both silver coated and uncoated regions contribute the impedance spectra. Probably $\mathrm{Si} / \mathrm{SiO}_{\mathrm{x}} / \mathrm{Ag} / \mathrm{Ag}_{2} \mathrm{O} / \mathrm{H}_{2} \mathrm{O}_{2}$ electrochemical chain provides smaller barrier as compared to direct electric double layer contact $\mathrm{Si} / \mathrm{SiO}_{\mathrm{x}} / \mathrm{H}_{2} \mathrm{O}_{2}$. However, in case of low frequencies the depletion of charge carriers from $\mathrm{Ag} / \mathrm{Si}$ results in limitation of carrier transport and $\mathrm{SiO}_{\mathrm{x}}$ layer capacitance growth.

To determine flat band potentials of p-doped $\mathrm{Si}$ and $\mathrm{Ag} / \mathrm{Si}$ electrodes Mott-Schottky measurements were performed at $1,000 \mathrm{~Hz}$. The choice of the frequency was dictated by the necessity to attain depletion of the charge carriers while avoiding diffusion limitations. Resulting plots for different $\mathrm{pH}$ of etching solutions and derived flat band potential values are summarized

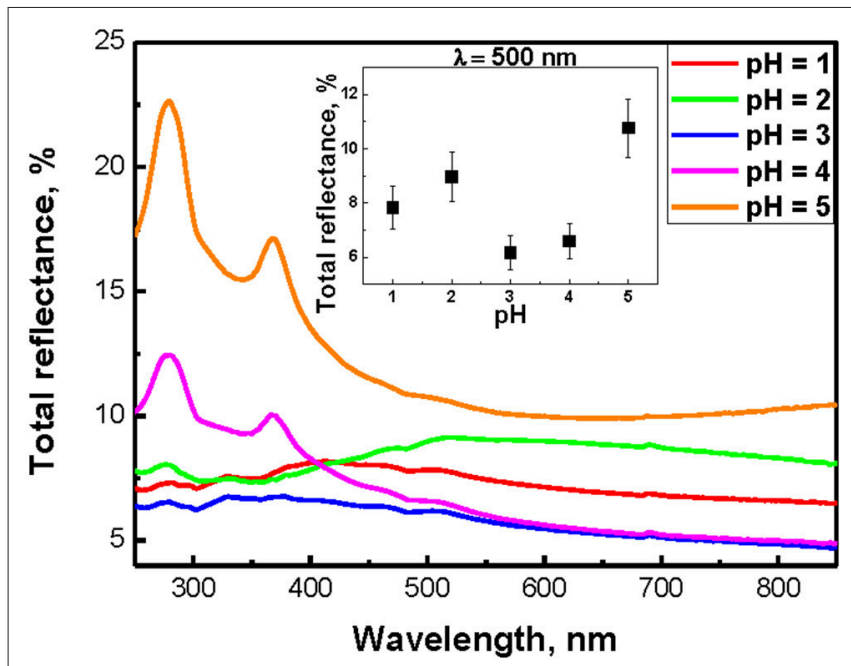

FIGURE 5 | Total reflectance spectra of SiNWs with different $\mathrm{pH}$ of $\mathrm{H}_{2} \mathrm{O}_{2}: \mathrm{NH}_{4} \mathrm{~F}$; inset shows the dependence of total reflection of SiNWs from the $\mathrm{pH}$ value of $\mathrm{H}_{2} \mathrm{O}_{2}: \mathrm{NH}_{4} \mathrm{~F}$. in Figure 4 and Table 1. One can see, the flat band potentials being $\mathrm{pH}$ dependent in case of etching of $\mathrm{p}$-doped silicon converge into closely the same value in case of $\mathrm{Ag} / \mathrm{Si}$. On the other hand, OCP values stay very close in both $\mathrm{p}-\mathrm{Si}$ and $\mathrm{Ag} / \mathrm{Si}$, with only small shift of OCP in case of $\mathrm{Ag} / \mathrm{Si}$. This effect corresponds well to smaller band bending and smaller capacitance of the interface layers. Thus, silver assisted chemical etching of silicon can be ascribed to facilitated transport through $\mathrm{Si} / \mathrm{SiO}_{\mathrm{X}} / \mathrm{Ag}$ interface.

Total reflectance spectra of SiNW layers are presented in Figure 5. All samples exhibit a strong decrease of the total reflectance to $5-10 \%$ at the wavelength $<850 \mathrm{~nm}$ in comparison to $\mathrm{c}$-Si substrate $(50 \%)$. At $\mathrm{pH}>3$, the total reflection spectra of nanowires have a very similar form with $\mathrm{c}$-Si, since for a weak submicron length SiNW, the c-Si substrate has a significant effect on the reflection value. Also in this case, reflection peaks appear at 280 and $370 \mathrm{~nm}$, which are associated with the c-Si direct band gap. Low total reflection of SiNW layers can be explained by the

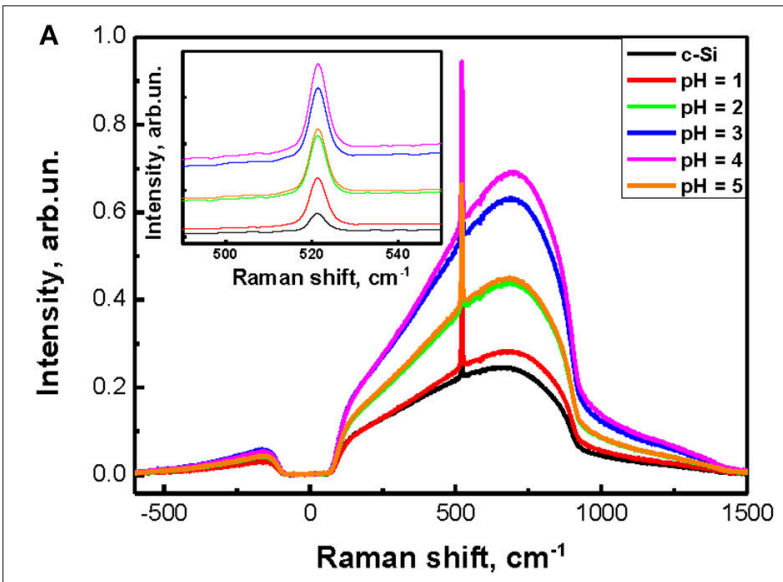

B

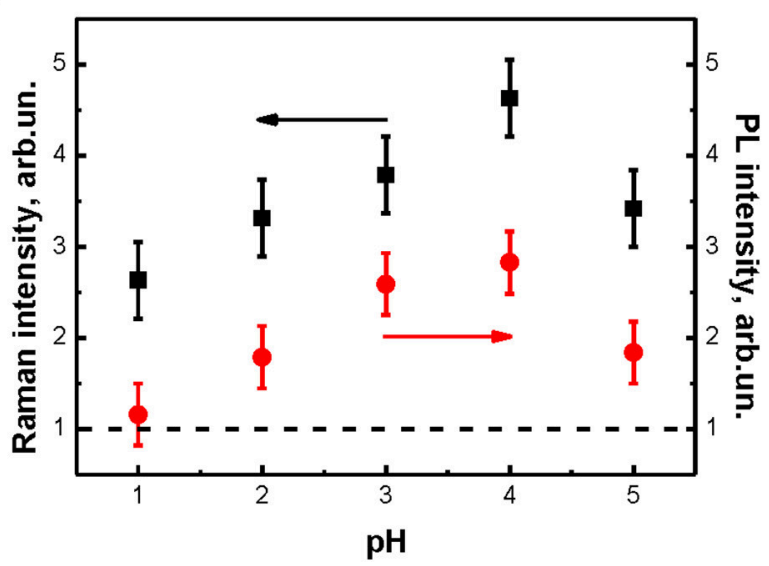

FIGURE 6 | (A) Spectra of interband PL and Raman scattering of C-Si substrate and $\mathrm{SiNWs}$ with different $\mathrm{pH}$ of $\mathrm{H}_{2} \mathrm{O}_{2}: \mathrm{NH}_{4} \mathrm{~F}$, inset shows Raman scattering peaks of $\mathrm{C}$-Si substrate and SiNWs with different $\mathrm{pH}$ of $\mathrm{H}_{2} \mathrm{O}_{2}: \mathrm{NH}_{4} \mathrm{~F}$. (B) The dependence of intensities of Raman scattering and interband $\mathrm{PL}$ of SiNWs from the $\mathrm{pH}$ value of $\mathrm{H}_{2} \mathrm{O}_{2}: \mathrm{NH}_{4} \mathrm{~F}$. 
strong scattering and absorption of light in the visible region of the spectrum, which can lead to a partial localization of light in nanowires (Gonchar et al., 2012). The inset in Figure 5 shown the dependence of the total reflection of SiNWs at $500 \mathrm{~nm}$ from the $\mathrm{pH}$ value of $\mathrm{H}_{2} \mathrm{O}_{2}: \mathrm{NH}_{4} \mathrm{~F}$. It is seen that for this wavelength, all samples have the same low values of the total reflectance (5-10\%).

The spectra of interband PL (broad peak) and Raman scattering (sharp peak at $520 \mathrm{~cm}^{-1}$ ) of the $\mathrm{c}$-Si substrate and a number of SiNW grown at different $\mathrm{pH}$ values are shown in Figure 6A. The inset in Figure 6A shows a close view of the Raman scattering peaks. SiNW's diameter is about $50-200 \mathrm{~nm}$ and far from the quantum confinement regime. That's why peaks and shapes of the interband PL and Raman scattering for all samples are similar to $\mathrm{c}$-Si. At the same time the intensities of interband PL and Raman scattering for SiNWs increase strongly as opposed to corresponding value for $\mathrm{c}$-Si. This effect can be explained by the light localization in such inhomogeneous optical medium as SiNW layers (Gonchar et al., 2014).

Figure 6B shows the calculated from Figure 6A dependence of SiNW's Raman scattering and interband PL intensities from the $\mathrm{pH}$ value. The signal intensity of the samples here was normalized to the signal intensity of c-Si substrate (dash line). Thus, the intensity of Raman scattering and interband PL increases by $3-5$ times and 3 times, respectively, for all SiNWs layers in comparison with c-Si. Let's remember, that the shape and length of SiNWs is changed with the increasing of $\mathrm{pH}$ value of $\mathrm{H}_{2} \mathrm{O}_{2}: \mathrm{NH}_{4} \mathrm{~F}$ : the length is decrease and the shape is changing from vertical cilinders to pyramidal like structures (see Figure 1. Based on this, we can conclude that the intensity of Raman scattering and interband PL depends not only on the length of SiNW, but also on their shape.

\section{CONCLUSION}

The structural and optical properties of SiNWs, prepared by the metal assisted chemical etching method, where the commonly used hydrofluoric acid (HF) has been successfully replaced with ammonium fluoride $\left(\mathrm{NH}_{4} \mathrm{~F}\right)$, and their dependence from the $\mathrm{pH}$ of the etching $\mathrm{H}_{2} \mathrm{O}_{2}: \mathrm{NH}_{4} \mathrm{~F}$ solutions were studied in detail for

\section{REFERENCES}

Bai, F., Li, M., Huang, R., Song, D., Jiang, B., and Li, Y. (2012). Template-free fabrication of silicon micropillar/nanowire composite structure by one-step etching. Nanosci. Res. Lett. 7:557. doi: 10.1186/1556-276x-7-557

Bertolini, J. C. (1992). Hydrofluoric acid: a review of toxicity. J. Emergency Med. 10, 163-168. doi: 10.1016/0736-4679(92)90211-B

Brönstrup, G., Jahr, N., Leiterer, C., Csáki, A., Fritzsche, W., and Christiansen, S. (2010). Optical properties of individual silicon nanowires for photonic devices. ACS Nano 4, 7113-7122. doi: 10.1021/nn101076t

Bruggeman, D. A. G. (1935). Berechnung verschiedener physikalischer konstanten von heterogenen substanzen. Ann. Phys. 24, 636-679. doi: 10.1002/andp.19354160705

Cao, A., Sudhölter, E. J., and de Smet, L. C. (2015). Silicon nanowire-based devices for gas-phase sensing. Sensors 14, 245-271. doi: 10.3390/s140100245

Chattopadhyay, S., Li, X., and Bohn, P. W. (2002). In-plane control of morphology and tunable photoluminescence in porous silicon produced by the first time. It is shown that as the $\mathrm{pH}$ of $\mathrm{H}_{2} \mathrm{O}_{2}: \mathrm{NH}_{4} \mathrm{~F}$ decrease, the shape of the nanowires changes from pyramidal to vertical. The length of SiNW arrays demonstrated non-linearly $\mathrm{pH}$ dependence. By impedance and Mott-Schottky measurements it was shown that the $\mathrm{SiO}_{\mathrm{x}}$ layer thickness and electrolyte potential are strongly affected by $\mathrm{pH}$. With increasing $\mathrm{pH}$ of electrolyte OCP of the cell decreases reducing silicon oxidation rate. Silver assisted chemical etching of silicon can be ascribed to facilitated charge carriers transport through $\mathrm{Si} / \mathrm{SiO}_{\mathrm{x}} / \mathrm{Ag}$ interface. All samples exhibit a strong decrease of the total reflectance to 5$10 \%$ at the wavelength $<800 \mathrm{~nm}$ in comparison to c-Si substrate. Also the intensities of interband PL and Raman scattering for SiNWs increase strongly as opposed to corresponding value for c-Si, but depends both from the length and the shape of SiNWs: they were larger for long pyramidal nanowires. This effect can be explained by the light localization in such inhomogeneous optical medium as SiNW layers Thus, SiNW, manufactured using weakly toxic $\mathrm{NH}_{4} \mathrm{~F}$, have great potential for applications in the field of photovoltaics, photonics, and sensorics.

\section{AUTHOR CONTRIBUTIONS}

KG and VK performed SiNWs fabrication, optical measurements, and data analysis. GZ performed the SEM measurements. AE performed impedance and Mott-Schottky measurements. KG and LO performed the general data analysis and discussion of the obtained data. All authors read and approved the final manuscript.

\section{FUNDING}

This work was supported by the Russian Science Foundation (Grant No. 17-12-01386).

\section{ACKNOWLEDGMENTS}

The equipment of the Educational and Methodical Center of Lithography and Microscopy, M. V. Lomonosov Moscow State University Research Facilities Sharing Center was used. metal-assisted electroless chemical etching. J. Appl. Phys. 91, 6134-6140. doi: 10.1063/1.1465123

Cui, Y., Wei, Q., Park, H., and Lieber, C. M. (2001). Nanowire nanosensors for highly sensitive and selective detection of biological and chemical species. Science 293, 1289-1292. doi: 10.1126/science.1062711

Dawood, M. K., Tripathy, S., Dolmanan, S. B., Ng, T. H., Tan, H., and Lam, J. (2012). Influence of catalytic gold and silver metal nanoparticles on structural, optical, and vibrational properties of silicon nanowires synthesized by metal-assisted chemical etching. J. Appl. Phys. 112:073509. doi: 10.1063/1.47 57009

Dittrich, T., Rauscher, S., Timoshenko, V. Y., Rappich, J., Sieber, I., Flietner, H., et al. (1995). Ultrathin luminescent nanoporous silicon on $\mathrm{n}-\mathrm{Si}$ : $\mathrm{pH}$ dependent preparation in aqueous $\mathrm{NH}_{4} \mathrm{~F}$ solutions. Appl. Phys. Lett. 67, 1134-1136. doi: $10.1063 / 1.114985$

Föll, H., Hartz, H., Ossei-Wusu, E., Carstensen, J., and Riemenschneider, O. (2010). Si nanowire arrays as anodes in Li ion batteries. Phys. Status Solidi RRL 4, 4-6. doi: 10.1002/pssr.200903344 
Georgobiani, V. A., Gonchar, K. A., Zvereva, E. A., and Osminkina, L. A. (2018). Porous silicon nanowire arrays for reversible optical gas sensing. Phys. Stat. Sol. A 215:1700565. doi: 10.1002/pssa.201700565

Gonchar, K. A., Osminkina, L. A., Galkin, R. A., Gongalsky, M. B., Marshov, V. S., Timoshenko, V. Y., et al. (2012). Growth, structure and optical properties of silicon nanowires formed by metal-assisted chemical etching. J. Nanoelectr. Optoelectr. 7, 602-606. doi: 10.1166/jno.2012.1401

Gonchar, K. A., Osminkina, L. A., Sivakov, V., Lysenko, V., and Timoshenko, V. Y. (2014). Optical properties of nanowire structures produced by the metalassisted chemical etching of lightly doped silicon crystal wafers. Semiconductors 48, 1613-1618 doi: 10.1134/S1063782614120082

Gonchar, K. A., Zubairova, A. A., Schleusener, A., Osminkina, L. A., and Sivakov, V. (2016). Optical properties of silicon nanowires fabricated by environmentfriendly chemistry. Nanosci. Res. Lett. 11:357. doi: 10.1186/s11671-016-1568-5

Gorostiza, P., Diaz, R., Kulandainathan, M. A., Sanz, F., and Morante, J. R. (1999). Simultanius platinum deposition and formation of a photoluminescent porous silicon layer. J. Electroanal. Chem. 469, 48-52. doi: 10.1016/S0022-0728(99)00189-8

Jiang, Y., Shen, H., Zheng, C., Pu, T., Wu, J., Rui, C., et al. (2017). Nanostructured multi-crystalline siliconsolar cell with isotropic etchingby $\mathrm{HF} / \mathrm{KMnO}_{4}$. Phys. Status Solidi A 214:1600703. doi: 10.1002/pssa.201600703

Judge, J. S. (1971). A study of the dissolution of $\mathrm{SiO}_{2}$ in acidic fluoride solutions. J. Electrochem. Soc. 118, 1772-1775. doi: 10.1149/1.2407835

Kelzenberg, M. D., Turner-Evans, D. B., Kayes, B. M., Filler, M. A., Putnam, M. C., Lewis, N. S., et al. (2008). Photovoltaic measurements in single-nanowire silicon solar cells. Nano Lett. 8, 710-714. doi: 10.1021/nl072622p

Li, X., and Bohn, P. W. (2000). Metal-assisted chemical etching in $\mathrm{HF} / \mathrm{H}_{2} \mathrm{O}_{2}$ produces porous silicon. Appl. Phys. Lett. 77, 2572-2574. doi: $10.1063 / 1.1319191$

Morinaga, H., Futatsuki, T., Ohmi, T., Fuchita, E., Oda, M., and Hayashi, C. (1995). Behavior of ultrafine metallic particles on silicon wafer. Surface J. Electrochem. Soc. 142, 966-970. doi: 10.1149/1.2048569

Nahidi, M., and Kolasinski, K. W. (2006). Effects of stain etchant composition on the photoluminescence and morphology of porous silicon. J. Electrochem. Soc. 153, C19-C26. doi: 10.1149/1.2129558

Peng, K. Q., Hu, J. J., Yan, Y. J., Wu, Y., Fang, H., Xu, Y., et al. (2006). Fabrication of single-crystalline silicon nanowires by scratching a silicon surface with catalytic metal particles. Adv. Funct. Mater. 16, 387-394. doi: 10.1002/adfm.200500392
Peng, K. Q., Lu, A. J., Zhang, R. Q., and Lee, S. T. (2008). Motility of metal nanoparticles in silicon and induced anisotropic silicon etching. Adv. Funct. Mater. 18, 3026-3035. doi: 10.1002/adfm.200800371

Peng, K. Q., Yan, Y. J., Gao, S. P., and Zhu, J. (2002). Synthesis of largearea silicon nanowire arrays via self-assembling nanoelectrochemistry. Adv. Mater. 14, 1164-1167. doi: 10.1002/1521-4095(20020816)14:16<1164::AIDADMA1164>3.0.CO;2-E

Sivakov, V., Andrä, G., Gawlik, A., Berger, A., Plentz, J., Falk, F., et al. (2009). Silicon nanowire-based solar cells on glass: synthesis, optical properties, and cell parameters. Nano Lett. 9, 1549-1554. doi: 10.1021/nl803641f

Sivakov, V. A., Bronstrup, G., Pecz, B., Berger, A., Radnoczi, G. Z., Krause, M., et al. (2010). Realization of vertical and zigzag single crystalline silicon nanowire architectures. J. Phys. Chem. C 114, 3798-3803. doi: 10.1021/jp90 9946x

Stelzner, T., Pietsch, M., Andrä, G., Falk, F., Ose, E., and Christiansen, S. H. (2008) Nanotechnology 19:295203. doi: 10.1088/0957-4484/19/29/295203

Wagner, R. S., and Ellis, W. C. (1964). Vapor-liquid-solid mechanism of single crystal growth. Appl. Phys. Lett. 4, 89-90. doi: 10.1063/1.1753975

Wang, X., and Ozkan, C. S. (2008). Multisegment nanowire sensors for the detection of DNA molecules. Nano Lett. 8, 398-404. doi: 10.1021/nl071180e

Yang, P., Yan, R., and Fardy, M. (2010). Semiconductor nanowire: what's next? Nano Lett. 10, 1529-1536. doi: 10.1021/nl100665r

Zhang, M. L., Peng, K. Q., Fan, X., Jie, J. S., Zhang, R. Q., Lee, S. T., et al. (2008). Preparation of large-area uniform silicon nanowires arrays through metal-assisted chemical etching. J. Phys. Chem. C 112, 4444-4450. doi: $10.1021 /$ jp077053o

Conflict of Interest Statement: The authors declare that the research was conducted in the absence of any commercial or financial relationships that could be construed as a potential conflict of interest.

Copyright (c) 2019 Gonchar, Kitaeva, Zharik, Eliseev and Osminkina. This is an open-access article distributed under the terms of the Creative Commons Attribution License (CC BY). The use, distribution or reproduction in other forums is permitted, provided the original author(s) and the copyright owner(s) are credited and that the original publication in this journal is cited, in accordance with accepted academic practice. No use, distribution or reproduction is permitted which does not comply with these terms. 